\title{
Evaluation of Sediment Transport in the Naiband Gulf Area Using Mike21
}

\author{
Parviz Soltani', Mehdi Behdarvandi Askar ${ }^{2 *}$, Hossein Bahrami ${ }^{2}$, Sadegh Haghighi Pour ${ }^{3}$ \\ ${ }^{1}$ Coastal Engineering, Khorramshahr University of Marine Science and Technology, Khorramshahr, Iran \\ ${ }^{2}$ Department of Offshore Structures, Faculty of Marine Engineering, Khorramshahr University of Marine Science and Technology, \\ Khorramshahr, Iran \\ ${ }^{3}$ Department of Civil Engineering, Khuzestan University Jihad Higher Education Center, Khuzestan, Iran \\ Email: *sazehenteghal@yahoo.com
}

How to cite this paper: Soltani, P., Askar, M.B., Bahrami, H. and Pour, S.H. (2017) Evaluation of Sediment Transport in the Naiband Gulf Area Using Mike21. Open Journal of Geology, 7, 182-192. https://doi.org/10.4236/ojg.2017.72012

Received: January 26, 2017

Accepted: February 24, 2017

Published: February 27, 2017

Copyright $\odot 2017$ by authors and Scientific Research Publishing Inc. This work is licensed under the Creative Commons Attribution International License (CC BY 4.0).

http://creativecommons.org/licenses/by/4.0/ (c) (i) Open Access

\begin{abstract}
Naiband Gulf is part of Naiband National Park known as Iran's first marine national park. It is Iran's most important habitats in the northern Persian Gulf due to mangrove forests, coral community, and community of marine animals. The study examines the sediment transport in the Naiband Gulf and around it, where to achieve this. First, the required data including coastline information, sediment profile, and bathymetry information and waves are obtained. Then by Mike21, 2011 Version models, it was attempted to simulate waves and currents due to it in the coastal zone to determine the rate and direction of sediment transport in the Naiband Gulf area. The results obtained in this study indicate that the majority of sediment transport directions on both sides of the gulf have been internal. The existence of structures in the north and south of the Gulf has reduced alongshore sediment flows and sedimentation, especially in the south of the gulf that is a serious threat to corals.
\end{abstract}

\section{Keywords}

Naiband Gulf, Mike21 Software, Sediment Transport, Ecosystem

\section{Introduction}

Marine-coastal areas are considered the most productive and dynamic ecological resources and pave the way for massive socio-economic activities in the world. These areas are dynamic places of the cross-function of land, water, and atmosphere that are also affected by permanent natural changes and human activities. Coastal and marine areas with their unique and significant biodiversity, in terms of conservation, have long been neglected and received irreparable harms. Although the marine and coastal habitats in Agenda 21 of the Rio have been de- 
scribed fragile and vulnerable, they have a very small share of the global network of protected areas. Therefore, identification of sensitive marine-coastal areas has been considered as a way to protect sensitive areas of the marine environment and turn them into conservation areas [1]. In the Persian Gulf and the Oman Sea, there are two unique habitats that are ecologically, socially, economically, and scientifically important. According to estimates by the International Union for Conservation of Nature (IUCN), in the last 20 years, more than 93 countries, including Iran, have destroyed their coral reefs vastly and intensely. Based on this estimate, more than $30 \%$ of the world's coral reefs in the next 15 years will be destroyed if the trend continues, and up to 50 years in the future, this figure will include $75 \%$ of coral reefs. This study is carried out using data of Ports and Maritime Organization (PMO) and numerical modeling of sediment in the Naiband Gulf pattern so that the results are used to reduce the damage to the area [2].

\section{Materials and Research Methods}

In this research, given the great importance of Naiband Gulf (Figure 1) ecosystem and its surrounding and the maintenance of this national park, we examine sediment transport in the Gulf of Naiband. To do so, we first achieve the required data including coastline information, sediment profile, bathymetry information, and waves then by using Mike21 model, we try to simulate the waves and the consequent flows in coastal areas to determine the rate and direction of sediment transport in the Gulf. Compound section is referred to a section the surface of which is made of several sub-sections with different flow characteristics [3]. The difference in the hydraulic and geometry characteristics causes a complexity in flow hydraulic and creates an interaction between the main channel and floodplains, resulting in an apparent shear stress and a transverse momentum transfer [4]. The study area is Naiband Gulf located in the Persian Gulf with geographical location $27^{\circ} 25^{\prime} 0 " \mathrm{~N}$ and $52^{\circ} 35^{\prime} 0^{\prime \prime} \mathrm{E}$ located in Assaluyeh in South East Bushehr province that is on the list of small bays and covers an area of approximately 4127 hectares [5]. The intended slopes for seawalls were 22, 27, 32, 39 degrees, respectively and had theroughness heights on wall surface were $15 \mathrm{~cm}, 20 \mathrm{~cm}$ and $30 \mathrm{~cm}$. Moreover, four types of roughness layouts on the wall surface were investigated [6]. Designing see platform stands has always appealed to a large number of engineers active in the field, because see platforms are one of the most important types of offshore structures for utilization of oil and gas resources [7]. The humans' need to use the oceans for exploration and extraction of oil has led to the development of engineering science in the field of offshore structures [8]. A wide range of studies have been conducted in a fore mentioned parameters followed by the complexity connection with symmetrical compound rectangular of the hydraulic flow [9].

The first step in numerical simulation of marine phenomena and the design of mathematical models is providing coordinate information of the different parts of the sea floor level (Bathymetry) as one of the study area boundaries. In other words, the exact determination of the depth of water in all parts of the study area 


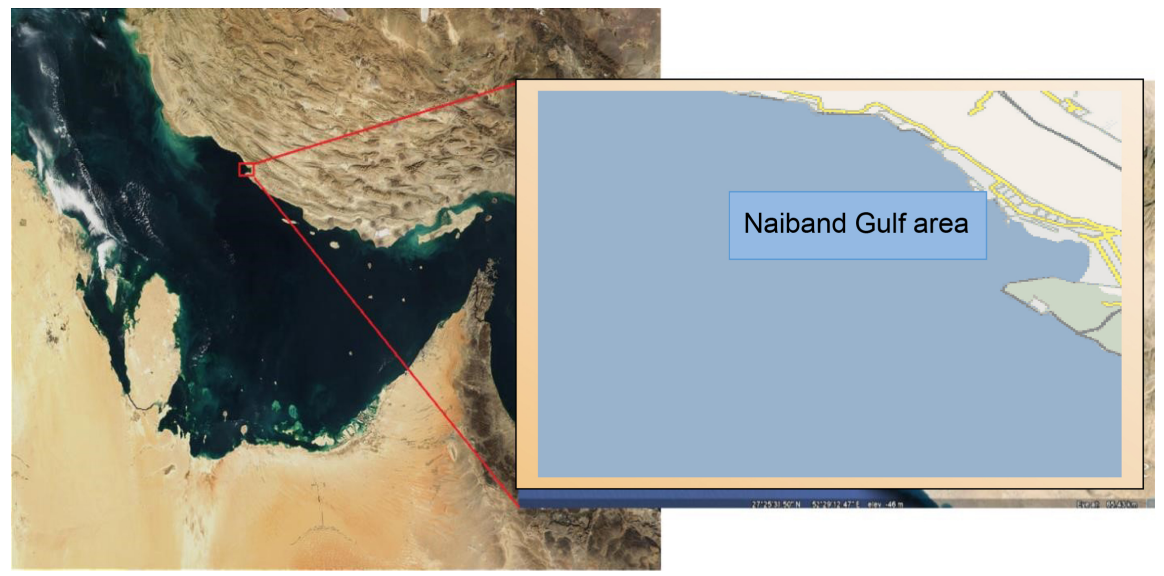

Figure 1. The location of the cities and villages around.

is considered the most important step in hydrodynamic modeling. Dimensions of the elements designed are variable according to the type of the issues mentioned above and are in areas adjacent to coastal and shallow water about 50 meters deep in areas with dimensions of approximately 250 meters [10].

Figure 2 shows boundaries of meshed network environment and solutions. In the blue border, boundary conditions of the wave will be defined offshore and on the red and green borders, the boundary condition is defined as lateral, and finally yellow border is the border of our coastline. Determining the wave profile of the project area, such as height, period and direction of the wave is the most important part of the research [11]. To calculate the wave parameters, in addition to knowing modeling aspects and having bathymetry data, having the wind data of the area is necessary as well. Pre-determined data of deep-water wave simulation waves of monitoring project of Bushehr has been used in modeling the waves transferred into the gulf. The above-mentioned modeling is one-year prediction of the waves in the Persian Gulf created by the PMO. In Figure 3, an example of pre-determined information of the waves in monitoring project of $\mathrm{Bu}$ shehr in 52.5 longitudes and 27.4 latitudes, which is considered as boundary conditions of the waves used, is presented. The time series form of the wave of the area for one year is shown in Figure 3. The main differentiation stages compound with regular and typical sections of the same phenomenon is also hence the use of conventional hydraulic relationships associated with the regular channels, the compound channels, in combination with a significant incidence of errors [12].

Most waves enter the area from the West and to some extent the northwest and the southeast part of the Naiband Gulf after going round the nose into this area. More than 59 percent of the time at this one year time, wave heights is less than 0.5 meters, which represents the relative calmness of the area from the perspective of waves [13]. The authors have conducted flume experiments to simulate sediment transport of channel flows with tall rigid stems. These flows were examined for various stem densities, channel slopes and sediment sizes with uniformly-distributed unsubmergedcylind-rical rigid stems forming a regular square 


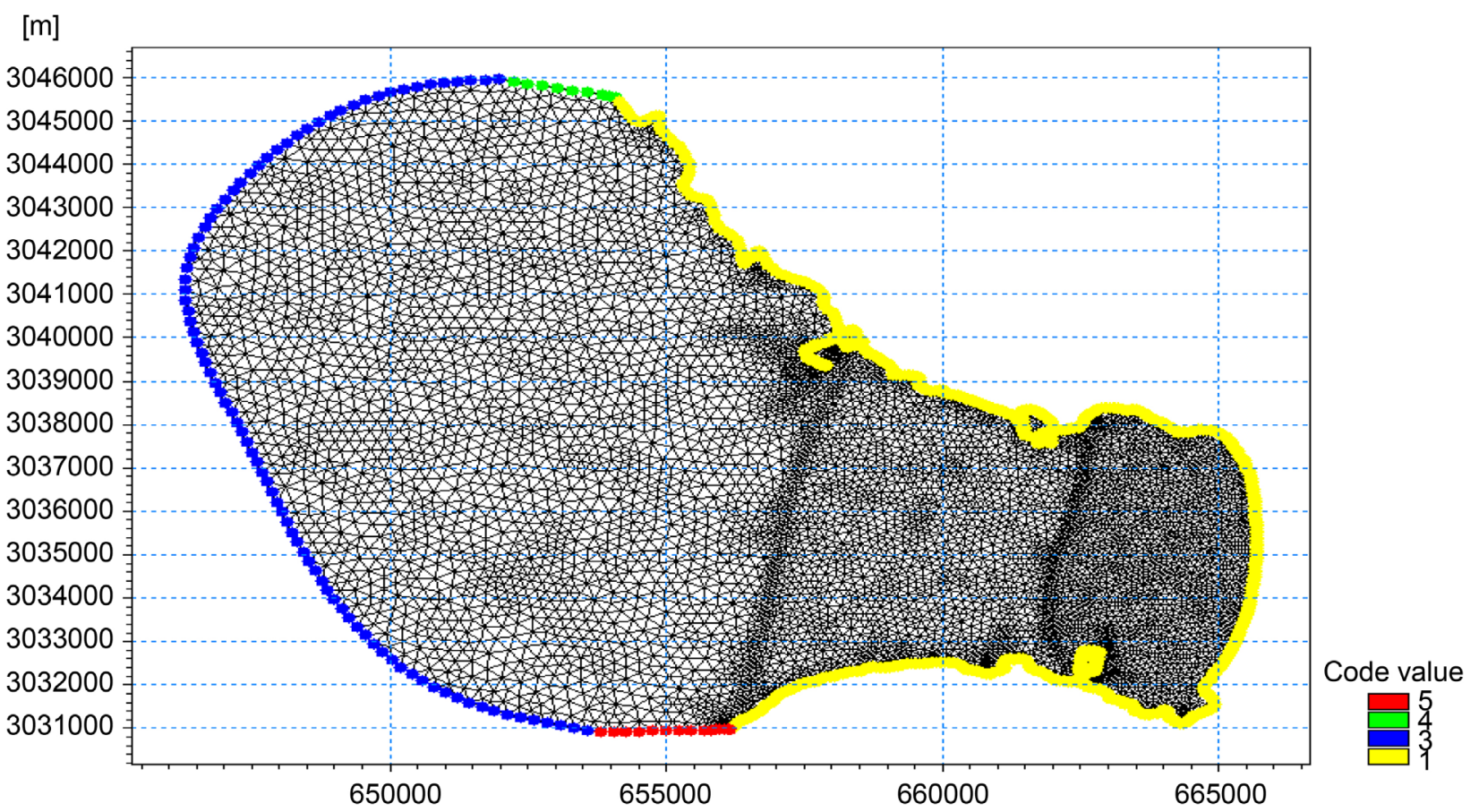

Figure 2. Meshing and boundries within the Naiband Gulf using Mikezero.

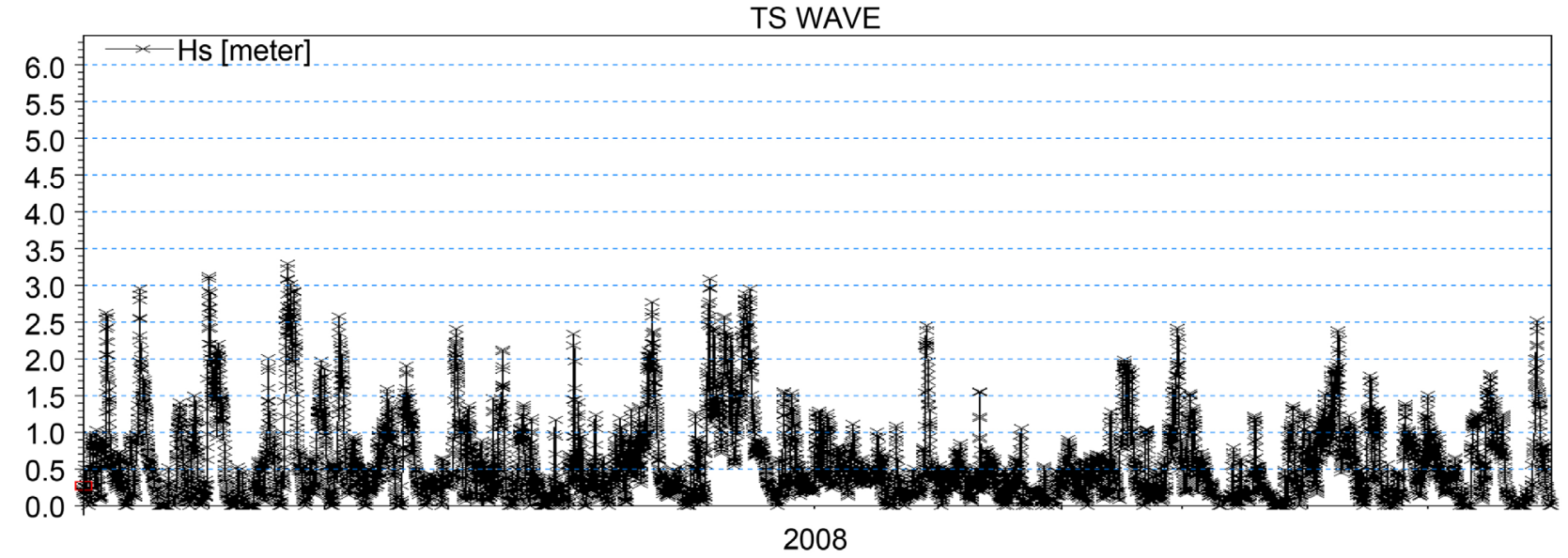

Figure 3. Annual change (sample) of the prediction of wave-the entry of the local model of wave in Naiband Gulf.

staggering pattern in plan [14]. Moreover, it is observed that the high waves or storms enter Naiband Gulf from the West. One could also say that about 0.09 percent of the waves are higher than 3 meters, most of which these are produced and enter the Naiband Gulf in the direction of 292.2 to 270 degrees. Southeast waves have occurrence frequency and height much less than the western waves [15]. Given that the main and dominant cause of sediment transport in coastal areas is coastal waves and currents arising from it parallel to the beach given that in coastal areas of small gulfs tidal flows do not have a significant impact on sediment transport and tides are mostly effective in big gulfs and creeks, the changes caused by tidal and streams due to it were ignored in estimating sediment transport rate in this study. From among prominent mathematical models in the world 
in analyzing the phenomena governing the marine environment, mathematical model Mike21 is one of the most known ones. This computer program that is established by Danish Hydraulic Institute in cooperation with Water Quality Institute and developed over time has great graphics and computational capabilities in the field of modeling phenomena related to estuaries, lakes, areas of low deep coastal bays and seas. In this study, modules SW, HD, and ST and Mike21 software are used. An important point to remember is that the responsiveness of a mathematical model depends on simulation methods and input information of the model.

\section{Calibration of the Models}

To develop the model, we should have a relatively full knowledge of the processes, mathematical equations, and algorithms describing the processes because most mathematical models need to adapt and adjust to controlling parameters.

Parameter adjusting operations for the coordination and consistency of data, such as changes in water level, speed and direction of currents and so on are called adjusting or calibrating the model. In other words, the purpose of calibration is to minimize the difference between the predicted output in the model and field measurements. This may be done by measuring the exact parameter or by optimization methods.

In the modeling performed to calibrate the numerical model Mike, information received from the port authorities is used and the region has been modeling for a day and in 1-hour time steps for 24 time steps is shown in the following figures. The sampling point in the gulf is in latitude and latitude Western 664,773 and 3,036,935 north. From the following table, it can be found that the Nikuardes factor considered can show how much of the friction in the Naiband Gulf.

According to Figure 4 showed that at the beginning of the modeling, the error rate is very high, but over time, the error reduces because the flow keep its Characteristic. As a result, it seems that the best coefficient is from 0.009 to 0.0085 and 0.009 coefficient is used. As can be seen, at the beginning of the mode-

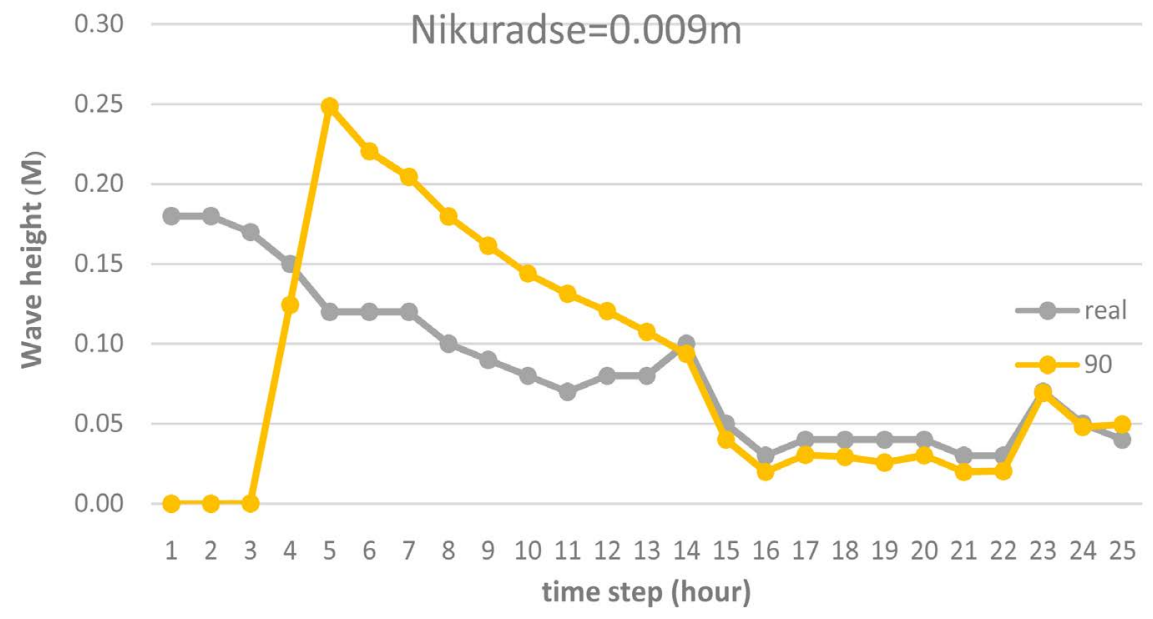

Figure 4. Calibration graphs for the study area. 
ling, the error rate is very high, but over time, the error reduces. In ST module, it is assumed that substrate materials are non-adherent, but sediment particle size can be different in different evaluated areas. In ST module performance model first potential of sediment transport is calculated in each of the study areas using input data. The most important factor in non-cohesive sediment transport in the coastal area is waves. Moreover, major side effects of waves occur on the bed in the Surf Zone (area between the waves and coastline failure). Thus, determining the characteristics of the waves near the coast, especially in the range of Surf Zone is necessary. In addition, due to the impact of phenomena such as shallow area, bottom friction, refraction and breaking waves on the waves in the coastal zone, simultaneous analysis of these effects is necessary. Thus, in this study, SW module of Mike21 software capable of considering all these phenomena is used to determine the specifications mentioned in the coastal area of wave propagation model. According to the above and studying the considered waves including 135 and 157.5 degree were considered as a representative of Southeast waves, and directions $202.5,180,225,247.5,270$, and 292.5 as waves of western area. It should be noted that sectors considered were 22.5 degrees.

\section{Results}

In Figure 5, a sub-example of the output of sw module including the contours of height for the entire range of simulation and the gulf are provided as examples. The outputs have been selected for two scenarios that seem to have much impact on sediment transport in the region. Scenario number 14, where about $30 \%$ during the year, this wave is present in the area is important because of the frequent incidence.

As can be seen, input wave intensity to the gulf in scenario number 14 at the

[m]

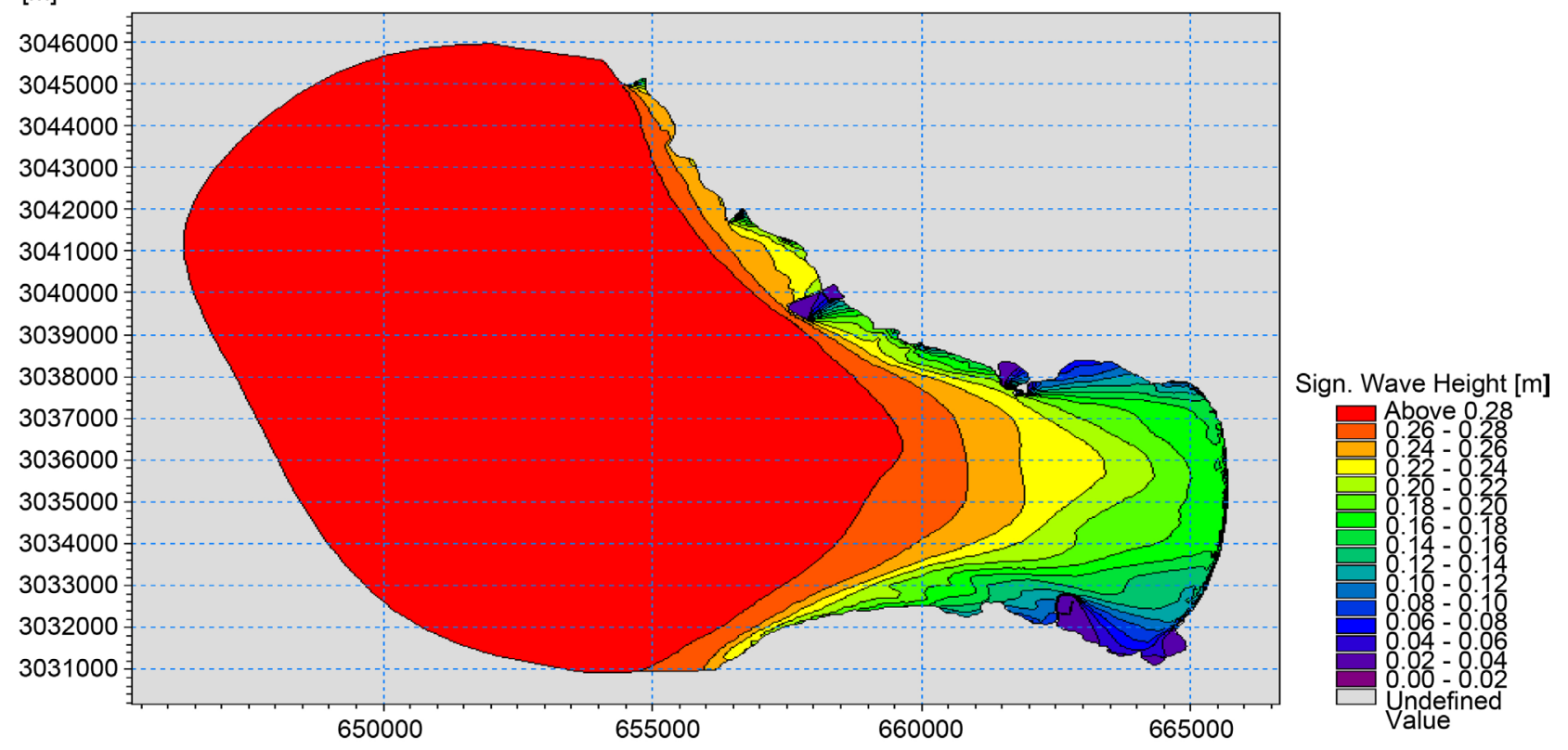

Figure 5. Contour of wave height simulated for scenario 14. 
entrance of the gulf is about $28 \mathrm{~cm}$ and this wave height is not capable of carrying large sediment. However, since nearly 100 days a year this wave exists in the region, it is anticipated that a significant sediment transport is imagined for this scenario.

In Figure 6, as can be seen, flows have been formed parallel to the coast in northern and southern part of the gulf coast and have good speed to carry sedimentation. As can be seen, in the South of the gulf, flow rate reduces when reaching Halo Port is halo greatly, and this indicates that Halo Port has an effective role on the coastal flows. In addition, due to the conical shape of the gulf, which is visible in Figure 6, the port (Assaluyeh Port) that is in the northern part of the gulf does not have a great impact on the speed of coastal flows, and coastal flows path will not be interrupted by the port. The port only diverts the flow regime in north of the gulf that, in this case, is the point opposite the southern state of the gulf, and the southern part of Halo Port cuts off the flow regime and flows generally stop behind the port. From the above it can be concluded that a significant percentage of sediments are deposited in behind the southern port but in the northern part of the port, sediments pass from the harbor. As can be seen in Figure 7, sediment transport rates close to the beach (in Surf Zone) is much higher than the rate of sediment transport in deep waters. This is for two reasons: first, according to what was said in the section on streaming, alongshore currents waves caused by the failure rate in this area are more than deep-water areas. Secondly, in areas near the coast due to the low water depth, due to the existence of substrate, particles are suspended in the presence of waves, concentration of suspended sediment goes high, and bed load verge of moving constituent particles occurs earlier. These factors together increase sediment transport rates in shallow

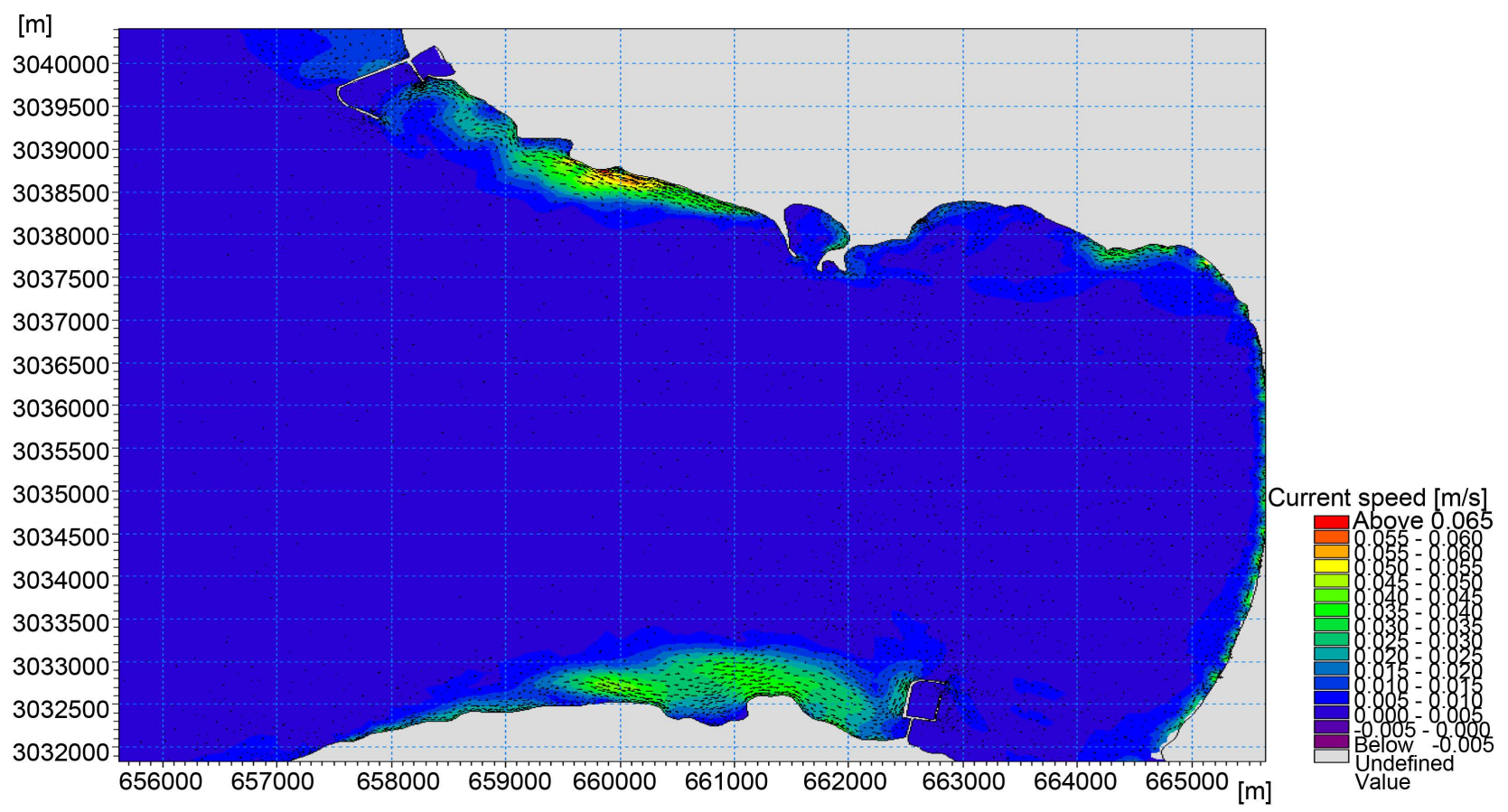

Figure 6. The contours of the flow rate simulated for scenario 14 . 


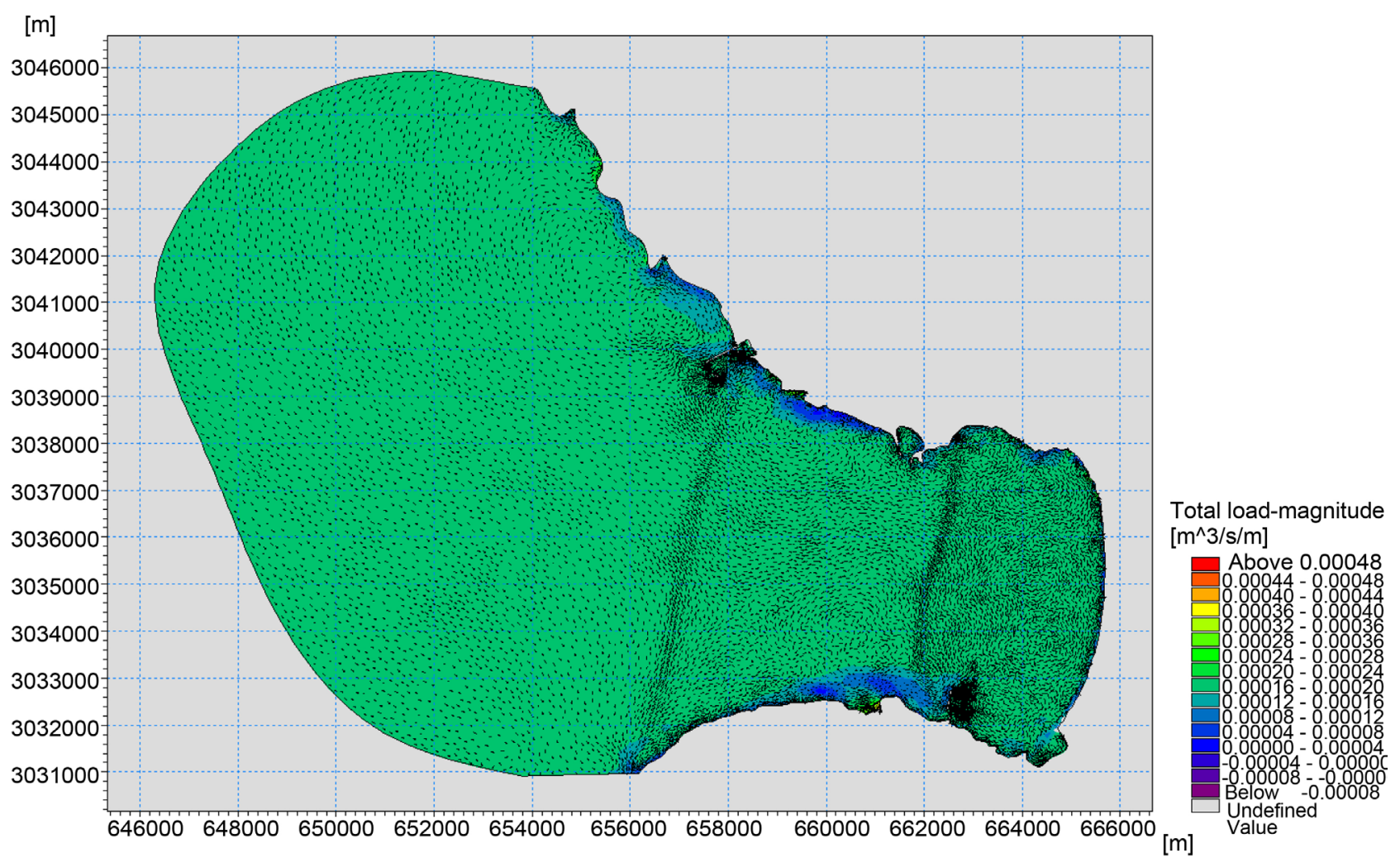

Figure 7. The contours of the amount and direction of the current total load (suspended and bed) for scenario 14.

coastal areas. Usually, the highest amount of sediment transport rates happens on Breaking Line.

As was expected from the hydrodynamic models, alongshore sediment (Figure 8) are carried by the stream parallel to the coast and in the north of the gulf, these flows go to the port in the north of the gulf and go inward. However, in the south of the gulf after flows reaching Halo Port, flow has stopped flowing into the harbor zone and in Figure 7; it is visible that in the amount of sediment passing through East and West of the port there are a lot of differences. In short, this means that in scenario No. 14 in the south of the gulf and behind Halo Port, sedimentation occurs. In order to better understand the levels of transport rates and better investigate this phenomenon, sediment transportation rates of alongshore flows for different directions are calculated on lines perpendicular to the coast in Naiband Gulf. After extracting these values for various scenarios, sediment transport rate is calculated based cubic meters for one year. To do this, the number of sediment transport in number in seconds for one year $(3600 \times 24 \times 365)$ and finally on the frequency of its occurrence scenario and then multiplied by numbers corresponding to the depth of the aggregate of all scenarios (taking into account the positive and negative directions).

Alongshore sediment transport rate according to the above mentioned was drawn for depth of 5 meters for extraction and modeling results are presented in the following Table 1. As can be seen, coastal sediments decrease by entering the gulf area. 
The above results show that the amount of sediment in the north of the gulf is less than south of Naiband. However, the port built in the south of the gulf makes a greater impact on the bottom sediments of the northern port of gulf (line 2), so a significant percentage of sediment that enters the south stop and deposited in the port zone, but sediment enter from the north of the gulf and deposit there. Moreover, Naiband Gulf due to the shallow depth is affected by sediments perpendicular to the beach and a significant amount of sediment at the bottom of the gulf are due to deposits perpendicular to the beach that can be seen in output images of sediment transport model pre-rendered.

\section{Discussion and Conclusion}

In this study, we tried to study the sediment of the area using Mike21 mathematical simulation tools. At first, the status of regional waves was analyzed based on available information and scenarios were defined for effective waves (wave with above height and frequency of occurrence). Using SW modules, wave propagation simulation was undertaken. Then using hydrodynamic module of this software and consequently sediment transport module, the wave-induced currents and sediment transport were calculated. At the end, the amount of this sediment transport for a scenario such as that, was obtained and collected together. Simulation results show that the dominant directions of transport are from the two

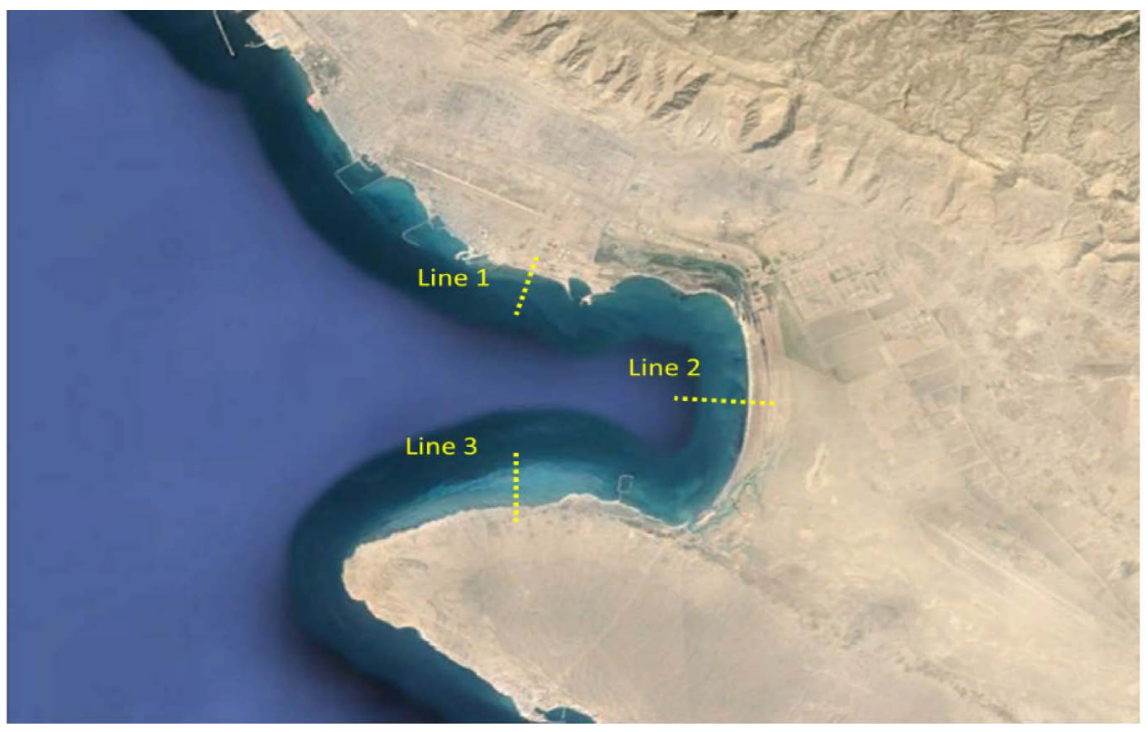

Figure 8. Positions of lines perpandacular to the coast to calculate longshore sediment transport rate.

Table 1. Estimated sediment transport rates.

\begin{tabular}{ccc}
\hline $\begin{array}{c}\text { The coastal sediment } \\
\text { transport directions }\end{array}$ & $\begin{array}{c}\text { Estimatedamount } \\
\text { (cubic meters per year) }\end{array}$ & Section \\
West to East & $101,167.9$ & Line 1 \\
North to south & $187,063.2$ & Line 2 \\
West to East & $145,984.94$ & Line 3 \\
\hline
\end{tabular}


sides of the gulf inward. The existence of structures in north of the gulf (Sepah Port and the ports of the South Pars) and the south of the gulf (Halo Port) has reduced transport rates on both sides of the gulf and at the entry of the gulf. Sedimentation in the back of the ports and their shape largely confirm this. About the constructions of the southern part of the gulf, it is necessary to note that due to the fact that the majority of corals are located in this section, there is a fear that cutout longshore sediment and sedimentation in these areas may have a serious risk for the destruction of these valuable organisms of the region.

\section{References}

[1] Chegini, V. (2012) Wind Waves and Predict Them in the Persian Gulf. Ghasemzadeh, N.M. Analyze What and Certain MH, 2012, to Investigate the Effects of Long Wharf on the East Coast of Bandar Abbas Coastline Change Case Study. The 10 th International Conference on Coasts, Ports and Marine Structures, Tehran, 19-21 November 2012, 23-34.

[2] Yazdanparast, A.A. and Soltanpour, M. (2012) The Impact of Erosion on the Coastal Cliffs Fouling Fishing Port Cook. 9th International Conference on Coasts, Ports and Marine Structures, Tehran, 29 November-1 December 2010, 40-52.

[3] Bahadori, S. and Askar, M.B. (2016) Investigating the Effect of Relative Depth and Relative Roughness on Momentum Transfer in Symmetric Rectangular Compound Channels with Various Relative Width. International Journal of Hydraulic Engineering, 5, 1-8.

[4] Bahadori, S. and Askar, M.B. (2016) Investigating the Effect of Relative Width on Momentum Transfer between Main Channel and Floodplain in Rough Rectangular Compound Channel Sunder Various Relative Depth Condition. Open Journal of Geology, 6, 225. https://doi.org/10.4236/ojg.2016.64020

[5] Deilami-Tarifi, M., et al. (2016) Modeling of the Changes in Flow Velocity on Seawalls under Different Conditions Using FLOW-3D Software. Open Journal of Marine Science, 6, 317-322. https://doi.org/10.4236/ojms.2016.62026

[6] Ebrahimi, A., et al. (2015) Investigation of Various Random Wave Run-Up Amounts under the Influence of Different Slopes and Roughnesses. Environment Conservation Journal, 16, 301-308.

[7] Ghatarband, M. and Askar, M.B. (2016) Investigation of the Effect of the Circular Stands Diameters of Marine Structures and the Distances between Them on Wave Run-Up and Force. Marine Science, 6, 11-15.

[8] Rashidinasab, M. and Askar, M.B. (2017) Modeling the Pressure Distribution and the Changes of Water Level around the Offshore Platforms Exposed to Waves, Using the Numerical Model of Flow 3D. Computational Water, Energy, and Environmental Engineering, 6, 97-106.

[9] Bahadori, S. and Askar, M.B. (2016) Investigating the Effect of Latitudinal Slope of Floodplain and Relative Roughness on Apparent Shear Stress in Symmetric Compound Rectangular Channels with Various Relative Width. Journal of Engineering and Applied Sciences, 11, 57-62.

[10] Mifoor, I., et al. (2016) On the Investigation of Basic Parameters of Designing Protective Layer of the Offshore Breakwaters at Iran's Kharg Island. International Journal of Recent Scientific Research, 7, 9821-9823.

[11] Bahadori, S. and Askar, M.B. (2015) Investigating the Simultaneous Effect of Relative Width and Relative Roughness on Apparent Shear Stress in Symmetric Com- 
pound Rectangular Channels. Journal of Current Research in Science, 1, 654-660.

[12] Askar, M.B. and Moghadam, M.F. (2013) Momentum Attraction by Flood Plains in Compound Channel. Journal of Engineering and Technology, 2, 7-15.

[13] Deilami-Tarifi, M., et al. (2015) Effect of Slope, Size, and Arrangement of Roughness of Sea Wall on Overtopping of Random Waves. International Journal of Biology, Pharmacy and Applied Sciences, 4, 1026-1034.

[14] Fathi-Moghadam, M., et al. (2010) Effect of TALL Vegetation on Sediment Transport by Channel Flows. Journal of Hydraulic Research, 48, 831-832. https://doi.org/10.1080/00221686.2010.534265

[15] Askar, M.B. and Moghadam, M.F. (2014) Studying Momentum Transfer between the Sub-Sections of a Symmetric Compound Rectangular Section Using Force Measurement Method. Indian Journal of Scientific Research, 4, 248-257.

Submit or recommend next manuscript to SCIRP and we will provide best service for you:

Accepting pre-submission inquiries through Email, Facebook, LinkedIn, Twitter, etc. A wide selection of journals (inclusive of 9 subjects, more than 200 journals)

Providing 24-hour high-quality service

User-friendly online submission system

Fair and swift peer-review system

Efficient typesetting and proofreading procedure

Display of the result of downloads and visits, as well as the number of cited articles

Maximum dissemination of your research work

Submit your manuscript at: http://papersubmission.scirp.org/

Or contact ojg@scirp.org 